\title{
Some Fixed Point Theorems in Complete Dislocated Quasi-b-metric Space
}

\author{
Hao $\mathrm{Wu}^{1} \&$ Dingping $\mathrm{Wu}^{2}$ \\ ${ }^{1}$ School of Applied Mathematics, Chengdu University of Information Technology, Chengdu 610225, China \\ ${ }^{2}$ School of Applied Mathematics, Chengdu University of Information Technology, Chengdu 610225, China \\ Correspondence: Hao Wu, School of Applied Mathematics, Chengdu University of Information Technology, No.24 Block \\ 1, Xuefu Road, Chengdu 610225, China. E-mail: wuha90@163.com
}

Received: June 6, 2016 Accepted: June 27, 2016 Online Published: July 25, 2016

doi:10.5539/jmr.v8n4p68

URL: http://dx.doi.org/10.5539/jmr.v8n4p68

\begin{abstract}
In this paper, we main introduced some concepts and Ciric cyclic fixed point theorem in the complete dislocated quasi-bmetric space. We also can improve some fixed point theorems by Ciric cyclic fixed point theorem such as Kannan cyclic fixed point theorem. It is consist with [Klin-Eam. C, 2016]. Our results for such space consist with the metric space. And our theorems generalization and extend some results in the literature.
\end{abstract}

Keywords: fundamental mathematics, fixed point, dislocated quasi-b-metric space, Ciric cyclic contraction, Kannan cyclic contraction, Hardy-Roges cyclic contraction, Zamfirescu cyclic contraction

\section{Introduction}

It is well-known that fixed point theory is an important mathematical displine. It has been study extensively. The metric space is very clearly and some contraction have only one fixed point in metric space, such as Ciric contraction [Ciric, 1974; Senapati. T, 2016]. And Ciric contraction includes Kannan contraction [Choudhury. B. S, 2014], Hardy-Roges contraction [Kumari. P. S, 2016] and Zamfirescu contraction [Zamfirescu. T, 1972]. So the Ciric fixed point theorem can deduces the Kannan fixed point theorem, Hardy-Roges fixed point theorem and Zamfirescu fixed point theorem. They all the classical fixed point theorems in metric space. For the past years, some new type of metric spaces was introduced. Such as quasi-metric space was introduced in [Alegre. C, 2015; Gaba. Y. U, 2016; Liu Z, 1997; Noorwali. M, 2016], dislocated metric space was introduced in [Pasicki. L, 2015] and b-metric space was introduced in [Zhu. C, 2014]. In [Klin-Eam. C, 2015] introduce a new metric space called dislocated quasi-b-metric space. It is more generalization than others. In this paper, we main introduced Ciric cyclic fixed point theorem in complete dislocated quasi-b-metric space. And deduces some fixed point theorems such as Kannan cyclic fixed point theorem, Hardy-Roges cyclic fixed point theorem and Zamfirescu cyclic fixed point theorem. Our result generalization and consists the fixed point theorems with metric space.

\section{Preliminaries}

Definition 1 Let $X$ is non-empty set, $w: X^{2} \rightarrow[0, \infty)$, such that there exist a constant $\alpha>1$, satisfied as follow:

(i) $w(x, y)=w(y, x)=0$ implies that $x=y$, for all $x, y \in X$;

(ii) $w(x, y) \leq \alpha[w(x, z)+w(z, y)]$, for all $x, y, z \in X$.

Then, we called $(X, w)$ is a dislocated quasi-b-metric space.

Definition 2 Let $(X, w)$ is a dislocated quasi-b-metric space, $\left\{x_{n}\right\}$ is a sequence in it.Then $x$ is called the limit of $\left\{x_{n}\right\}$, if

$$
\lim _{n \rightarrow \infty} w\left(x_{n}, x\right)=\lim _{n \rightarrow \infty} w\left(x, x_{n}\right)=0 .
$$

Definition 3 Let $(X, w)$ is a dislocated quasi-b-metric space, $\left\{x_{n}\right\}$ is a sequence in it, if

$$
\lim _{m, n \rightarrow \infty} w\left(x_{n}, x_{m}\right)=\lim _{n, m \rightarrow \infty} w\left(x_{m}, x_{n}\right)=0 .
$$

Then $\left\{x_{n}\right\}$ is called a cauchy sequence.

Definition 4 Let $(X, w)$ is a dislocated quasi-b-metric space, if all of the cauchy sequences are convergents in $X$, then 
$(X, w)$ is called the complete.

Definition 5 ([Klin-Eam, 2016])Let $(X, w)$ is a dislocated quasi-b-metric space, A and B are nonempty closed subsets in it. A map $T: A \cup B \rightarrow A \cup B$ is called cyclic map, if $T(A) \subseteq B$ and $T(B) \subseteq A$.

Definition 6 et $(X, w)$ is a dislocated quasi-b-metric space, A and B are nonempty closed subsets in it. A map $T$ is called Ciric cyclic contraction, if $T$ is a cyclic mapping on $A \cup B$ and exist $h \in(0,1)$, such that for $\alpha \geq 1, \alpha h<1$ and all $x \in A$, $y \in B$,

$$
w(T x, T y) \leqslant h \max \{w(x, y), w(x, T x), w(y, T y), w(x, T y), w(y, T x)\} .
$$

Definition 7 et $(X, w)$ is a dislocated quasi-b-metric space, A and B are nonempty closed subsets in it. A map $T$ is called Kannan cyclic contraction, if $T$ is a cyclic mapping on $A \cup B$ and exist $h \in\left[0, \frac{1}{2}\right)$, such that for $\alpha \geq 1, \alpha h<\frac{1}{2}$ and all $x \in$ $A, y \in B$,

$$
w(T x, T y) \leqslant h[w(x, T x)+w(y, T y)] .
$$

Definition 8 et $(X, w)$ is a dislocated quasi-b-metric space, A and B are nonempty closed subsets in it. $T$ is called HardyRoges cyclic contraction, if $T$ is a cyclic mapping on $A \cup B$ and exist $\sum_{i=1}^{5} a_{i}<1$ such that for $\alpha \geq 1, \sum_{i=1}^{5} \alpha a_{i}<1$ and all $x \in A, y \in B$,

$$
w(T x, T y) \leqslant a_{1} w(x, y)+a_{2} w(x, T x)+a_{3} w(y, T y)+a_{4} w(x, T y)+a_{5} w(y, T x) .
$$

Definition 9 Let $(X, w)$ is a dislocated quasi-b-metric space, A and B are nonempty closed subsets in it. $T$ is called Zamfirescu cyclic contraction, if $T$ is a cyclic mapping on $A \cup B$ and exist $h \in(0,1)$ such that for $\alpha \geq 1, \alpha h<1$ and all $x$ $\in A, y \in B$,

$$
w(T x, T y) \leqslant h \max \left\{w(x, y), \frac{1}{2}[w(x, T x)+w(y, T y)], \frac{1}{2}[w(x, T y)+w(y, T x)]\right\} .
$$

Lemma $1(X, w)$ is a dislocated quasi-b-metric space, $T$ is Ciric cyclic contraction in it, for $x \in X$ and all $1 \leq i, j \leq n, i, j$ $\in Z^{+}$. Then

$$
w\left(T^{i} x, T^{j} x\right) \leqslant h \delta\left(O^{T}(x ; 0, n)\right) .
$$

Which $O^{T}(x ; 0, n)=\left\{x, T x, T^{2} x, \ldots, T^{n} x\right\}$ and $\delta(H)=\sup \{w(x, y), x, y \in H\}$.

Proof.

$$
\begin{aligned}
w\left(T\left(T^{i-1} x\right), T\left(T^{j-1} x\right)\right) & \leq h \max \left\{w\left(T^{i-1} x, T^{j-1} x\right), w\left(T^{i-1} x, T^{i} x\right), w\left(T^{j-1} x, T^{j} x\right), w\left(T^{i-1} x, T^{j} x\right), w\left(T^{j-1} x, T^{i} x\right)\right\} \\
& \leq h \delta\left(O^{T}(x ; 0, n)\right) .
\end{aligned}
$$

Then, there exists some $1 \leq k_{i} \leq n$, such that

$$
M_{1}=\max \left\{w\left(x, T^{k_{1}} x\right), w\left(T^{k_{2}} x, x\right), w(x, x)\right\}=\delta\left(O^{T}(x ; 0, n)\right) .
$$

Lemma $2 \delta\left(O^{T}(x ; 0, \infty)\right) \leq M_{2} \frac{\alpha}{1-\alpha h}$. Which

$$
M_{2}=\max \{w(x, T x), w(T x, x), w(x, x)\} .
$$

Proof. From lemma 1, we obtain that

$$
\begin{gathered}
\delta\left(O^{T}(x ; 0,1)\right) \leq \delta\left(O^{T}(x ; 0,2)\right) \leq \ldots \leq \delta\left(O^{T}(x ; 0, n)\right) . \\
\delta\left(O^{T}(x ; 0, \infty)\right)=\sup \left\{\delta\left(O^{T}(x ; 0, n)\right), n=1,2, \ldots\right\} .
\end{gathered}
$$


When $\delta\left(O^{T}(x ; 0, n)\right)=w(x, x)$,

we obtain that

$$
\delta\left(O^{T}(x ; 0, \infty)\right) \leq M_{2} \frac{\alpha}{1-\alpha h} .
$$

When $\delta\left(O^{T}(x ; 0, n)\right)=w\left(x, T^{k_{1}} x\right)$,

we obtain that

$$
\begin{aligned}
w\left(x, T^{k_{1}} x\right) & \leq \alpha\left[w(x, T x)+w\left(T x, T^{k_{1}} x\right)\right] \\
& \leq \alpha w(x, T x)+\alpha h \delta\left(O^{T}(x ; 0, n)\right) \\
& =\alpha w(x, T x)+\alpha h w\left(x, T^{k_{1}} x\right) .
\end{aligned}
$$

Then

$$
w\left(x, T^{k_{1}} x\right) \leq \frac{\alpha}{1-\alpha h} w(x, T x) .
$$

Similarly, when $\delta\left(O^{T}(x ; 0, n)\right)=w\left(T^{k_{2}} x, x\right)$,

$$
w\left(T^{k_{2}} x, x\right) \leq \frac{\alpha}{1-\alpha h} w(T x, x) .
$$

So by (2), (3), (4),

$$
\delta\left(O^{T}(x ; 0, \infty)\right) \leq M_{2} \frac{\alpha}{1-\alpha h} .
$$

\section{Main Results}

Theorem $1(X, w)$ is a complete dislocated quasi-b-metric space, if $T$ is a Ciric cyclic contraction in it. Then, in $A \cap B$, $T$ has only one fixed point.

Proof. Let $x_{0} \in A($ fixed $)$, suppose $m \geq n$.

First, we will proof $\left\{T^{n} x_{0}\right\}$ are Cauchy sequence.

$\left.w\left(T^{m} x_{0}, T^{n} x_{0}\right)=w\left(T^{m-n+1}\left(T^{n-1} x_{0}\right), T\left(T^{n-1} x_{0}\right)\right) \leq h \delta\left(O^{T}\left(T^{n-1} x_{0}\right) ; 0, m-n+1\right)\right)$.

So from (1), for some $k_{i}, k_{j}, 1 \leq i, j \leq m-n+1$,

we have

$\delta\left(O^{T}\left(T^{n-1} x_{0} ; 0, m-n+1\right)\right)=$

$$
\max \left\{w\left(T^{n-1} x_{0}, T^{k_{i}}\left(T^{n-1} x_{0}\right)\right), w\left(T^{k_{j}}\left(T^{n-1} x_{0}\right), T^{n-1} x_{0}\right), w\left(T^{n-1} x_{0}, T^{n-1} x_{0}\right)\right\} .
$$

When $\delta\left(O^{T}\left(T^{n-1} x_{0} ; 0, m-n+1\right)\right)=w\left(T^{n-1} x_{0}, T^{k_{i}}\left(T^{n-1} x_{0}\right)\right)$,

as to

$$
\begin{aligned}
w\left(T^{n-1} x_{0}, T^{k_{i}}\left(T^{n-1} x_{0}\right)\right) & =w\left(T\left(T^{n-2} x_{0}\right), T^{k_{i}+1}\left(T^{n-2} x_{0}\right)\right) \\
& \leq h \delta\left(O^{T}\left(T^{n-2} x_{0} ; 0, k_{i}+1\right)\right) \\
& \cdots \\
& \leq h^{n} \delta\left(O^{T}\left(x_{0} ; 0, m\right)\right) .
\end{aligned}
$$

Similarly, when $\delta\left(O^{T}\left(T^{n-1} x_{0} ; 0, m-n+1\right)\right)=w\left(T^{k_{j}}\left(T^{n-1} x_{0}\right), T^{n-1} x_{0}\right)$,

$$
w\left(T^{k_{j}}\left(T^{n-1} x_{0}\right), T^{n-1} x_{0}\right) \leq h^{n} \delta\left(O^{T}\left(x_{0} ; 0, m\right)\right) .
$$


When $\delta\left(O^{T}\left(T^{n-1} x_{0} ; 0, m-n+1\right)\right)=w\left(T^{n-1} x_{0}, T^{n-1} x_{0}\right)$,

$$
\begin{aligned}
w\left(T^{m} x_{0}, T^{n} x_{0}\right) & \leq h w\left(T^{n-1} x_{0}, T^{n-1} x_{0}\right) \\
& =h w\left(T\left(T^{n-2} x_{0}\right), T\left(T^{n-2} x_{0}\right)\right) \\
& \leq h^{2} \delta\left(O^{T}\left(T^{n-2} x_{0} ; 0,1\right)\right) \\
& \cdots \\
& \leq h^{n} \delta\left(O^{T}\left(x_{0} ; 0, n\right)\right) \\
& \leq h^{n} \delta\left(O^{T}\left(x_{0} ; 0, m\right)\right)
\end{aligned}
$$

Thus, by (5), (6), (7), we have

$$
w\left(T^{m} x_{0}, T^{n} x_{0}\right) \leq h^{n} \delta\left(O^{T}\left(x_{0} ; 0, m\right)\right) .
$$

Similarly,

$$
w\left(T^{n} x_{0}, T^{m} x_{0}\right) \leq h^{n} \delta\left(O^{T}\left(x_{0} ; 0, m\right)\right) .
$$

Take $n \rightarrow \infty$, we get $w\left(T^{m} x_{0}, T^{n} x_{0}\right) \rightarrow 0$ and $w\left(T^{n} x_{0}, T^{m} x_{0}\right) \rightarrow 0$.

Since $(X, w)$ is complete, we obtain that $\left\{T^{n} x_{0}\right\}$ is Cauchy sequence.

Second, we note $\left\{T^{n} x_{0}\right\}$ converges to some $z \in X$. And $\left\{T^{2 n} x_{0}\right\}$ is a sequence in $A,\left\{T^{2 n-1} x_{0}\right\}$ is a sequence in $B$. It is all tends to the same limit $z$.

Consider

$$
w\left(T^{n} x_{0}, T z\right) \leq h \max \left\{w\left(T^{n-1} x_{0}, z\right), w\left(T^{n-1} x_{0}, T^{n} x_{0}\right), w(z, T z), w\left(T^{n-1} x_{0}, T z\right), w\left(z, T^{n} x_{0}\right)\right\} .
$$

Take limit as $n \rightarrow \infty$. we have

$$
w(z, T z) \leq h w(z, T z)
$$

as to $0 \leq h<1$, we have $w(z, T z)=0$.

Similarly,

$w\left(T z, T^{n} x_{0}\right) \leq h \max \left\{w\left(z, T^{n-1} x_{0}\right), w(z, T z), w\left(T^{n-1} x_{0}, T^{n} x_{0}\right), w\left(z, T^{n} x_{0}\right), w\left(T^{n-1} x_{0}, T z\right)\right\}$.

Take limit as $n \rightarrow \infty$. we have

$$
w(T z, z) \leq h w(z, T z)
$$

As to $w(z, T z)=0$, we have $w(T z, z)=0$.

Third, we prove $z$ is the only one fixed point. Suppose there have another fixed point $z^{*} \in X$ on $T$, such that $T z^{*}=z^{*}$.

$$
w\left(z, z^{*}\right)=w\left(T z, T z^{*}\right) \leq h \max \left\{w\left(z, z^{*}\right), w\left(z^{*}, z\right)\right\}
$$

and

$$
w\left(z^{*}, z\right)=w\left(T z^{*}, T z\right) \leq h \max \left\{w\left(z, z^{*}\right), w\left(z^{*}, z\right)\right\} .
$$

Then

$$
\begin{aligned}
& w\left(z, z^{*}\right) \leq h\left[w\left(z, z^{*}\right)+w\left(z^{*}, z\right)\right] ; \\
& w\left(z^{*}, z\right) \leq h\left[w\left(z, z^{*}\right)+w\left(z^{*}, z\right)\right] .
\end{aligned}
$$

We have 


$$
\begin{aligned}
& w\left(z, z^{*}\right) \leq \frac{h}{1-h} w\left(z^{*}, z\right) ; \\
& w\left(z^{*}, z\right) \leq \frac{h}{1-h} w\left(z, z^{*}\right) .
\end{aligned}
$$

We obtain that $w\left(z, z^{*}\right)=w\left(z^{*}, z\right)=0$.

Hence, $z$ is the only one fixed point of $T$. The proof are completes.

Corollary $1(X, w)$ is a complete dislocated quasi-b-metric space, if $T$ is Kannan cyclic contraction in it. Then, $T$ has only one fixed point in $A \cap B$.

Corollary $2(X, w)$ is a complete dislocated quasi-b-metric space, if $T$ is Hardy-Roges cyclic contraction in it. Then, $T$ has only one fixed point in $A \cap B$.

Corollary $3(X, w)$ is a complete dislocated quasi-b-metric space, if $T$ is Zamfirescu cyclic contraction in it. Then, $T$ has only one fixed point in $A \cap B$.

\section{Discussion}

Example 1 Let $X=[-1,1], T: X \longrightarrow X$ defined by $T x=-\frac{x}{5}$ and $x \in A, y \in B$, if $A=[-1,0], B=[0,1]$, then $T x \in B$ and $T y \in A$, defined $w: X^{2} \rightarrow[0, \infty)$ that

$$
w(x, y)=|x-y|^{2}+4|x|+3|y|
$$

Proof. It is clearly that $(X, w)$ is a complete dislocated quasi-b-metric space and $T$ is a cyclic map on $X$.

Thus,

$$
\begin{aligned}
w(T x, T y) & =|T x-T y|^{2}+4|T x|+3|T y| \\
& =\frac{1}{25}|x-y|^{2}+\frac{4}{5}|x|+\frac{3}{5}|y| \\
& \leq \frac{1}{25}(|x|+|y|)^{2}+\frac{4}{5}|x|+\frac{3}{5}|y| \\
& \leq \frac{2}{25}|x|^{2}+\frac{2}{25}|y|^{2}+\frac{4}{5}|x|+\frac{3}{5}|y| \\
& \leq \frac{2}{25}\left[\frac{36}{25}|y|^{2}+4|y|+\frac{3}{5}|y|\right]+\frac{2}{25}\left[\frac{36}{25}|x|^{2}+4|x|+\frac{3}{5}|x|\right] \\
& \leq \frac{2}{25}[w(y, T y)+w(x, T x)] \\
& \leq \frac{2}{25}[w(x, y)+w(x, T x)+w(y, T y)+w(x, T y)+w(y, T x)]
\end{aligned}
$$

As to $\frac{2}{25} \times 5<1$,

then

$$
\begin{aligned}
w(T x, T y) & =|T x-T y|^{2}+4|T x|+3|T y| \\
& \leq \frac{2}{25}[w(x, y)+w(x, T x)+w(y, T y)+w(x, T y)+w(y, T x)] \\
& \leq \frac{11}{25} \max \{w(x, y), w(x, T x), w(y, T y), w(x, T y), w(y, T x)\}
\end{aligned}
$$

$0 \leq h=\frac{11}{25}<1$. It is satisfied theorem 1 . Thus, 0 is the only one fixed point of $T$.

\section{References}

Alegre, C, \& Marłn. J. (2015). Modified w-distances on quasi-metric spaces and a fixed point theorem on complete quasi-metric spaces. Topology $\mathcal{E}$ Its Applications. http://dx.doi.org/10.1016/j.topol.2015.12.073 
Choudhury, B. S, \& Maity. P. (2014). Cyclic Coupled Fixed Point Result Using Kannan Type Contractions. Journal of Operators, 4, 1-5. http://dx.doi.org/10.1155/2014/876749

Ciric, Lj. B. (1974). A Generalization of Banach's Contraction Principle. Publications De L Institut Mathematique, 45(2): 267-273. http://dx.doi.org/10.1037/0033-2909. 126. 6. 910

Gaba, Y. U, \& Knzi, H. P. A. (2016). Partially ordered metric spaces produced by T0-quasi-metrics. Topology $\mathcal{E}$ Its Applications, 202, 366-383. http://dx.doi.org/10.1016/j.topol.2016.01.028

Klin-Eam, C, \& Suanoom, C. (2015). Dislocated quasi-b-metric spaces and fixed point theorems for cyclic contraction. Fixed Point Theory \& Applications, 1, 1-12. http://dx.doi.org/10.1186/s13663-015-0325-2

Klin-Eam, C., \& Kaskasem, P. (2016). Fixed Point Theorems for Cyclic Contractions in C -Algebra-Valued b -Metric Spaces. Journal of Function Spaces, 1-16. http://dx.doi.org/10.1155/2016/7827040

Kumari, P. S, \& Panthi. D. (2016). Connecting various types of cyclic contractions and contractive self-mappings with Hardy-Rogers self-mappings. Fixed Point Theory E Applications, 1, 1-19. http://dx.doi.org/10.1186/s13663-0160498-3

Liu, Z, \& Debnath L. (1997). On Characterizations of Common Fixed Points in General Quasi-Metric Spaces. Journal of Mathematical Analysis $\mathcal{E}$ Applications, 206(2), 345-351. http://dx.doi.org/10.1006/jmaa.1997.5186

Noorwali, M, Alsulami, H. H, \& Karapinar, E. (2016). Some Extensions of Fixed Point Results over Quasi-JS-Spaces. Journal of Function Spaces. http://dx.doi.org/10.1155/2016/6963041

Pasicki, L. (2015). Dislocated metric and fixed point theorems. Fixed Point Theory E Applications, 1, 1-14. http://dx.doi. org/10. 1186/s13663-015-0328-z

Senapati, T, Dey. L. K, \& Dolicanin-Dekic D.(2016). Extensions of Ciric and Wardowski type fixed point theorems in Dgeneralized metric spaces.Fixed Point Theory E Applications, 1, 1-14. http://dx.doi.org/10.1186/s13663-016-0522-7

Zamfirescu, T. (1972). Fix point theorems in metric spaces. Archiv Der Mathematik, 23(23), 292-298. http://dx.doi.org/10. 1007/bf01304884

Zhu, C, Chen, C, \& Zhang, X. (2014). Some results in quasi- b -metric-like spaces. Journal of Inequalities $\mathcal{E}$ Applications, 1, 1-8. http://dx.doi.org/10.1186/1029-242x-2014-437

\section{Copyrights}

Copyright for this article is retained by the author(s), with first publication rights granted to the journal.

This is an open-access article distributed under the terms and conditions of the Creative Commons Attribution license (http://creativecommons.org/licenses/by/4.0/). 